\title{
THE STUDY OF FECAL INCONTINENCE IN POST-OPERATIVE ANORECTAL MALFORMATIONS - A CLINICAL CORRELATION WITH MRI FINDINGS
}

\author{
Talari Vinod Kumar'1, Nagarjuna Kumbha², Rajesh Mallepalli3 , G. Rajendra Prasad ${ }^{4}$ \\ ${ }^{1}$ Assistant Professor, Department of Paediatric Surgery, Niloufer Hospital. \\ ${ }^{2}$ Associate Professor, Department of Paediatric Surgery, Niloufer Hospital. \\ ${ }^{3}$ Senior Resident, Department of Paediatric Surgery, Gandhi Medical College. \\ ${ }^{4}$ Professor, Department of Paediatric Surgery, Gandhi Medical College.
}

\section{ABSTRACT}

\section{BACKGROUND}

Imaging studies done in the postoperative Anorectal Malformation patients serve for the evaluation of the associated malformations and for the assessment of the causes for fecal incontinence including the complications of surgery. The objective of the study was to assess status of fecal continence in postoperative Anorectal malformation by correlating clinical evaluation with Magnetic Resonance Imaging (MRI) findings and to compare Kelly's score of continence with MRI scoring.

\section{MATERIALS AND METHODS}

The study includes 32 postoperative ARM patients, of three to fourteen years of age, who presented to Gandhi Medical College, Secunderabad over a period of 27 months. Children were clinically assessed for the continence by Kelly score and studied with MRI imaging for the location and morphology of neorectum, presence of scarring, presence of peritoneal fat herniation, development of the striated muscle complex and any other abnormalities.

\section{RESULTS}

Of the 32 patients, 10 cases presented with low, 20 with high and 2 patients with intermediate anorectal anomalies; 10 out of 32 patients (Low ARA-9, intermediate-1) following definitive surgery for anorectal malformations were assessed clinically as good, 7 (Intermediate ARA-1, low-1, high-5) were fair and 15 high ARA were poor. Sphincter muscle development was poor in 15 patients of high ARA, fair in 7 patients (Intermediate ARA-1, low-1, high-5) and good in 10 patients (Low-9, intermediate-1). On comparison of Kelly's continence score with MRI scoring, children with poor clinical continence score coincided with the poor muscle development, fair with fair muscle development and cases with good continence score had good muscle development. Of the 32 patients, 19 had fecal incontinence and 13 were continent. Of the thirteen, 10 were low ARA, 2 were intermediate and 1 was high anorectal anomaly.

\section{CONCLUSION}

Kelly's clinical continence score in post-operative ARM correlated well with MRI scoring of puborectalis and external sphincter measurement with good score coinciding with good muscle development.

\section{KEYWORDS}

Anorectal Malformation, Fecal Incontinence, MRI Score, Kelly's Score.

HOW TO CITE THIS ARTICLE: Kumar TV, Kumbha N, Mallepalli R, et al. The study of fecal incontinence in post-operative anorectal malformations - A clinical correlation with MRI findings. J. Evolution Med. Dent. Sci. 2016; 5(11):449-452,

DOI: $10.14260 /$ jemds/2016/103

\section{INTRODUCTION}

Standardized assessment of clinical outcome after repair of ARM is essential for appropriate quality control, and for comparing different treatment modalities. Clinical assessment is subjective and is biased by the observer. Therefore paediatric surgeons performing clinical research need scales and scores that provide reliable information on the condition and functional status of the patients.

Financial or Other, Competing Interest: None.

Submission 23-12-2015, Peer Review 19-01-2016,

Acceptance 25-01-2016, Published 05-02-2016.

Corresponding Author:

Dr. Nagarjuna Kumbha

4-7-12/53 Ravindra Nagar Colony,

Nacharam, Hyderabad-500076.

Department of Paediatric Surgery,

Gandhi Medical College/Hospital, Secunderabad

E-mail:nags_arjun@yahoo.co.in

DOI: $10.14260 /$ jemds/2016/103
Imaging studies in the post-operative assessment of ARM patient's serve two major functions; for the evaluation of the associated malformations and the assessment of the causes for fecal incontinence including the complications of surgery. The commonly employed imaging methods include defecography, contrast enhanced computerized tomography scan, MRI scan and ultrasonography including endorectal sonography. Of these, MRI scan is better with regard to the resolution of the images of the muscle complex and of the vertebra and spinal cord.

Abnormalities of the vertebra and spinal cord resulting in fecal incontinence carry a poor prognosis. Damages to the muscle complex during surgery are potentially repairable. In addition, these studies may reveal an excess of fat outside the neorectum, which prevents it from functioning as a cohesive unit. A misplaced bowel can be corrected surgically.

The present study is done to assess status of fecal continence in postoperative anorectal malformation by correlating clinical evaluation with Magnetic Resonance 
Imaging (MRI) findings and to compare Kelly's score of continence with MRI scoring.

\section{ABBREVIATIONS}

ARM - Anorectal malformation.

MRI - Magnetic resonance imaging.

\section{MATERIALS AND METHODS}

This study includes 32 children of three to fourteen years of age who presented to Gandhi Medical College and Hospital, Secunderabad over a period of 27 months. The cases included in this study were all the post-operative anorectal malformation cases who underwent definitive procedure and colostomy closure and cases with single stage repair done for low anorectal malformations. All types of postoperative anorectal malformation cases like high, intermediate, low anomalies were included in the study.

The definitive procedures done in these 32 children are posterior sagittal anorectoplasty, abdomino-perineal pull through, anal transposition and abdominal posterior sagittal anorectoplasty. The youngest child in this study group was 3 years old and oldest child was 14 years old. The relevant clinical data, diagnosis, operative details and findings were collected from the departmental ARM registry. Hospital departmental ethics committee clearance was obtained for this study. A written informed consent was taken.

The clinical evaluation was graded using Kelly's clinical score of continence.[1,2] Patients were categorized as good with a score of 5-6, fair with 3-4 and 0-2 were considered poor score.

1.5 Tesla MRI scan with super conducting system was used and $5 \mathrm{~mm}$ contiguous sections were obtained using a head or body coil according to the size of the patient. T1 weighted images with spin echo pulse sequences and short repetition time and echo time were obtained in all patients. T2 weighted MRI scan was done in selected patients. Axial, coronal T1 weighted images of the pelvis including the perineal region and sagittal sections were imaged in all patients.

The MRI findings noted in this study include location and morphology of neorectum, presence of scarring, presence of peritoneal fat herniation, development of puborectalis and external sphincter muscles, associated vertebral and spinal cord anomalies and any other abnormalities. The puborectalis and external sphincter muscles were evaluated on axial MRI images at the level of symphysis pubis, coccyx and the ischial rami.

MRI score was categorized as good if the sphincter muscles of ARM patients showed the same degree of development as those of the normal pelvis without ARM in children of same age group. MRI score was considered fair if the sphincter muscles were less developed and poor if the muscles were barely identified. Subsequently, the results of the Kelly's clinical score of continence were compared with the MRI scoring.

Depending on the sphincter muscle thickness we have adjusted the thickness of external anal sphincter and puborectalis of normal children, taken from the previous studies.[3] and graded the MRI score.

The thickness of external sphincter and puborectalis of normal children without anorectal anomaly of different age groups were graded as good, fair or poor as per the muscle measurement taken from previous studies (Shown on Table1).[3]

\begin{tabular}{|c|c|c|c|c|c|c|}
\hline \multirow[t]{2}{*}{ Age Group } & \multicolumn{2}{|c|}{ Good SMC } & \multicolumn{2}{|c|}{$\begin{array}{c}\text { Fai/Moderate } \\
\text { Hypoplasia }\end{array}$} & \multicolumn{2}{|c|}{$\begin{array}{c}\text { Poor/Severe } \\
\text { Hypoplasia }\end{array}$} \\
\hline & $\begin{array}{c}\text { EAS } \\
(\mathrm{mm})\end{array}$ & $\begin{array}{c}\text { PR } \\
(\mathrm{mm})\end{array}$ & $\begin{array}{c}\text { EAS } \\
(\mathrm{mm})\end{array}$ & $\begin{array}{c}\text { PR } \\
(\mathrm{mm})\end{array}$ & $\begin{array}{c}\text { EAS } \\
(\mathrm{mm})\end{array}$ & $\begin{array}{c}\text { PR } \\
(\mathrm{mm})\end{array}$ \\
\hline $6 m-3 y r s$ & $3 \pm 0.2$ & $3.1 \pm 0.3$ & $2-2.9$ & $2.1-3.1$ & $<2$ & $<2.1$ \\
\hline Upto 7 yrs & $3.4 \pm 0.3$ & $3.8 \pm 0.2$ & $2.4-3.3$ & $2.8-3.7$ & $<2.4$ & $<2.8$ \\
\hline Upto 14 yrs & $4.0 \pm 0.4$ & $4.7 \pm 0.4$ & $3-3.9$ & $3.7-4.6$ & $<3$ & $<3.7$ \\
\hline
\end{tabular}

(EAS-external anal sphincter, PR-puborectalis) (Values mentioned under Good SMC are mean with standard deviation).

\section{OBSERVATION AND RESULTS}

Of the 32 patients (24 males and 8 females), 10 cases presented with low, 20 with high, 2 patients with intermediate anorectal anomalies.

Ten out of 32 patients following definitive surgery for anorectal malformations were assessed clinically by Kelly's continent score as good, 7 fair and 15 were considered as poor score (Shown in Table 3). The number of cases with low anorectal malformations with good Kelly's score were 9, fair was 1 and none with poor score. One case with intermediate ARM had good Kelly's score, 1 had fair and none had poor score; 15 cases with high ARM had a poor Kelly's score, 5 had fair score and none had good score; 19 children had fecal incontinence and 13 were continent. Of the 13, 10 were low ARA, 2 were intermediate and 1 was high anorectal anomaly. MRI imaging study showed poor Sphincter muscle development in 15 high ARA, fair in 7 (high ARA-5, intermediate-1, low-1) and good in 10 patients (low ARA-9, intermediate-1) (Table 2). Of the patients with poor sphincter development, one case of high ARA had misplaced neoanorectum and another high ARA had vertebral anomaly.

\begin{tabular}{|c|c|c|c|}
\hline \multirow{2}{*}{$\begin{array}{c}\text { Anorectal } \\
\text { Anomaly }\end{array}$} & $\begin{array}{c}\text { Good } \\
\text { Sphincter } \\
\text { Muscle }\end{array}$ & $\begin{array}{c}\text { Fair } \\
\text { Sphincter } \\
\text { Muscle }\end{array}$ & $\begin{array}{c}\text { Poor } \\
\text { sphincter } \\
\text { muscle and } \\
\text { misplaced } \\
\text { neorectum }\end{array}$ \\
\hline Low & 9 & 1 & 0 \\
\hline Intermediate & 1 & 1 & 0 \\
\hline High & 0 & 5 & 15 \\
\hline Table 2: The MRI scoring in the 32 Post-Operative Arm \\
Patients
\end{tabular}

On comparison of Kelly's continence score with MRI scoring, children with poor clinical continence score coincided with the poor muscle development, fair with fair muscle development and cases with good continence score had good muscle development (As shown in Table 4). 
The results of Kelly's score given to all the 32 patients are shown in the Table 3.

\begin{tabular}{|c|c|c|c|}
\hline \multirow{2}{*}{$\begin{array}{c}\text { Anorectal } \\
\text { Anomaly }\end{array}$} & \multicolumn{3}{|c|}{ KELLY SCORE OF CONTINENCE } \\
\cline { 2 - 4 } & Good & Fair & Poor \\
\hline Low & 9 & 1 & 0 \\
\hline Intermediate & 1 & 1 & 0 \\
\hline High & 0 & 5 & 15 \\
\hline Table 3: Kelly's Score of Continence in the 32 Post- \\
Operative Arm Patients \\
\hline
\end{tabular}

On comparing Kelly's score with MRI scoring, the poor continence score coincided with the poor muscle development, fair continence coincided with fair muscle development and good continence score coincided with good muscle development; 19 out of 32 patients have history of incontinence and 13 patients are continent. [Table 4].

\begin{tabular}{|c|c|c|c|}
\hline \multirow{2}{*}{$\begin{array}{c}\text { KELLY SCORE OF } \\
\text { CONTINENCE }\end{array}$} & \multicolumn{3}{|c|}{$\begin{array}{c}\text { MRI SCORE OF SPHINCTER } \\
\text { MUSCLE THICKNESS }\end{array}$} \\
\cline { 2 - 4 } & GOOD & FAIR & POOR \\
\hline GOOD & 10 & 0 & 0 \\
\hline FAIR & 0 & 7 & 0 \\
\hline POOR & 0 & 0 & 15 \\
\hline Table 4: Comparison of Kelly's Score with the MRI \\
Scoring \\
\hline
\end{tabular}
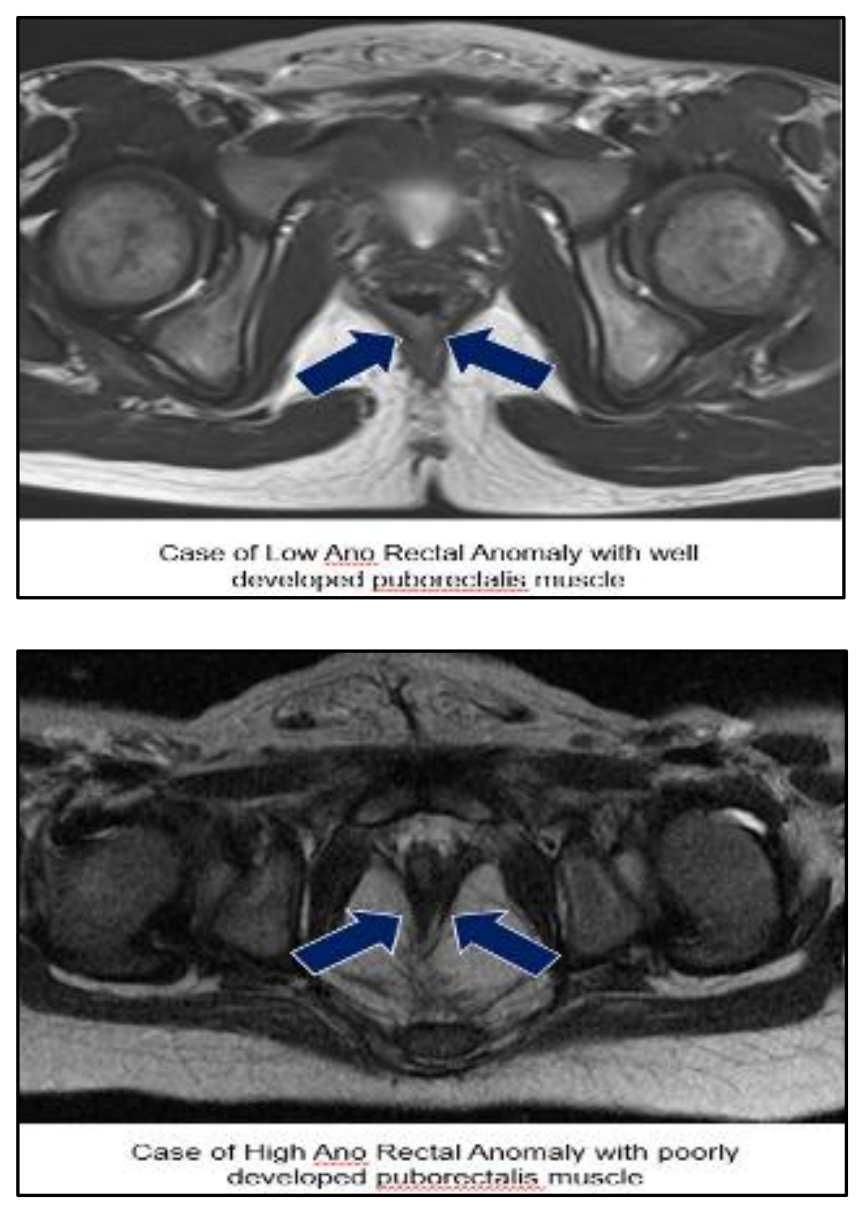

\section{DISCUSSION}

There are several factors related to continence: passive forces, motor action of the sphincter, function of the intestine and nervous system pathways.[1] The first two factors are essentially important in anorectal anomalies and can be correlated with the amount of muscle mass present in the sphincter. The puborectalis has been considered the essential muscle for continence and adequate placement of the neorectum in the puborectalis sling has been emphasized in the surgical literature.[1] Recently, the important contribution of the external anal sphincter for continence, particularly in the patients with anorectal anomalies has been stressed.[4,5] Adequate placement of the neorectum not only through the puborectalis sling, but also within the external sphincter muscle is necessary for an adequate functional outcome following surgical correction of the anorectal anomalies.

Several reports have assessed the efficacy of computed tomography and MRI in evaluating anorectal malformations. Most of them stressed that both computed tomography and MRI are valuable in imaging the relationship of the pulled bowel and sphincteric muscles.[6,7,8,9,10] With blind procedures such as abdominoperineal surgery, the pulled through intestine can be misplaced outside the puborectalis muscle. $[4,5]$ Misplaced neorectum can be detected easily by CT and MRI which probably is the most straight forward clinical application of these modalities. $[6,7,8,9,10]$

In the studies of Fukuya et al.[11] there were no patients with misplaced neorectum outside the levator ani muscle. But in the present study, 1 patient of high anorectal anomaly had misplaced neorectum for whom the Kelly's clinical score was poor and MRI scoring were assessed as fair. This patient had fecal incontinence and the cause could be either due to bowel misplacement or moderate muscle development noted in the MRI study. Redo pull-through was done and the child is under followup.

MRI has advantages over computed tomography because of its multiplanar imaging facility and lack of ionizing radiation for infants and small children. ${ }^{[9,10]}$ MRI is superior to computed tomography in identifying the sphincteric muscles due to its excellent soft tissue characterization.

Some previous studies have used the measurement of the thickness of the sphincteric muscles.[7,8] However, muscle thickness changes according to the patient's age. Some studies used subjective, visual imagination of the sphincteric muscles without measurements. ${ }^{66,7,10]}$ According to M. Hettiarachehi et al.[12] MRI scoring was given as 0-normal, 1-mild asymmetry, 2 -over $25 \%$ reduction in length or thickness of the sphincters compared to the contralateral side and 3 -over $50 \%$ reduction of muscles when compared to contralateral side.

According to the Fukuya et al.[11] MRI scoring was given as Good if the sphincter muscles of the ARM patient showed the same degree of development as those without anorectal malformation, Fair if sphincter muscle was less developed and poor if sphincter muscles are not seen or barely identified.

In the present study, the sphincter muscle measurement was done in accordance with the study of Shoatoa Tang, et al.[3] where the author measured the age related variations in thickness of external anal sphincter and puborectalis muscles in normal children. The muscle thickness was graded by keeping age adjusted range of thickness for external anal sphincter and puborectalis muscles and thereby MRI scoring was categorized as good, moderate/fair and poor/severe hypoplasia. The Kelly's score is then correlated with this MRI scoring.

T. Fukuya et al.[11] compared his MRI scoring with the Kelly's scoring system of continence. They indicated that there was no significant difference in development of the muscle with fair and poor scores. This may be due to small number of 
patients in their study. There was significant overlap between clinically continent and incontinent patients. This can be attributed to other factors affecting continence, such as innervation of the muscles. Poorly developed muscles were seen only in patients with fair or poor clinical scores. Grading based solely on the degree of development of muscles can be misleading unless there are markedly hypoplastic muscles.

In the present study there is a good correlation of MRI scoring with Kelly's clinical continent score.

Of the 32 patients in the present study, 19 were incontinent and all of these cases had high ARM. Of the 13 patients who were continent, 10 were low ARA, 2 were intermediate and 1 was high anorectal anomaly. The incontinence rate is high in our study when compared to other studies.[13] This may be because the patients who are symptomatic with incontinence have attended our hospital in more numbers when compared to asymptomatic patients.

In the present study, one patient with low ARM had hemivertebra at L5 with agenesis of the coccyx and patient is continent.

\section{CONCLUSION}

Kelly's clinical continence score in post-operative ARM correlated well with MRI scoring of puborectalis and external sphincter measurement with good score coinciding with good muscle development.

The incidence of fecal incontinence is high in postoperative ARM patients in the present study that is $59 \%$. All the low and intermediate ARA patients and one of the 20 patients with high ARA were continent. The cause of fecal incontinence in most of the post-operative ARM patients in this study is hypoplasia of the sphincter muscles and rarely bowel misplacement.

The incidence of associated spinal and vertebral anomalies is very low, that is $3.1 \%$.

\section{REFERENCES}

1. Stephens FD, Smith ED. Anatomy and function of the normal rectum and anus. In: Stephens FD, Smith ED, eds. Ano-rectal malformations in children. Chicago:Year Book Medical Publishers, 1971:14.
2. Ong N, Beasley SW. Comparison of clinical methods for the assessment of continence after repair of high anorectal anomalies. Pediatric surgery international. 1990;5:233-237.

3. Shao-Tao Tang, Qiang-Song Tong, Yong Wang, et al. Magnetic resonance imaging measurement of the anorectal striated muscle complex in normal children. J of Pediatric surgery 2006;41:1549-1555.

4. DeVries PA, Cox KL. Surgery of anorectal anomalies. Surg Clin North Am 1985;65:1139-1169.

5. Pena A. Posterior sagittal approach for correction of anorectal malformations. In: Mannic JA, Cameron JL, Jordan GL, Jr, et al. Advances in Surgery. Year Book, Chicago, 1986; P 69.

6. Kohda E, Fujioka M, Ikawa $\mathrm{H}$, et al. Congenital anorectal anomaly: CT evaluation. J Ped Radiology 1985;157:349-352.

7. Taccone A, Martucciello G, Fondelli P. CT of anorectal malformations; a postoperative evaluation. Pediatric radiology 1989;19:375-378.

8. Arnbjornsson E, Laurin S, Mikaelson C. Computed tomography of anorectal anomalies; correlation between radiological findings and clinical evaluation of fecal incontinence. Radiology 1989;30:25-28.

9. Vade A, Reyes H, Wilbur A, et al. The anorectal anomalies; MRI evaluation. Ped Radiology 1989;19:179-183.

10. Sato Y, Pringle KC, Bergman RA, et al. Congenital anorectal anomalies; MR imaging. Ped Radiology 1988;168:157-162.

11. Fukuya T, Honda H, Kubota M, et al. Postoperative MRI evaluation of anorectal malformations with clinical correlation. Pediatric radiology 1993;23:583-586.

12. Hettiarachchi M, Garcea G, De Souza NM, et al. Evaluation of dysfunction following reconstruction of an anorectal anomaly. Pediatric Surg Int 2002;18:405-409.

13. Holschneider AM, Koebke J, Meier-Ruge W, et al. Pathophysiology of chronic constipation in anorectal malformations. Long term results and preliminary anatomical investigations. Eur J Ped Surgery 2001;11:305-310. 